\title{
One-Dimensional Inclusion Polymerization of Diene and Vinyl Monomers by Using Methyl Cholate as a Host
}

\author{
Wyjayanthi Goonewardena, Mikiji Miyata,* and Kiichi Takemoto \\ Department of Applied Fine Chemistry, Faculty of Engineering, \\ Osaka University, Suita, Osaka 565, Japan.
}

(Received December 28, 1992)

\begin{abstract}
Inclusion polymerization of diene and vinyl monomers by using methyl cholate (MC) as a host was studied. The polymerization exhibited a number of behaviors characteristic of one-dimensional inclusion polymerization. For example, polymerizabilities of the monomers depended on their size and shape rather than their electronic properties. Another is that thermally stable propagating radicals were detected by ESR spectroscopy. These features resemble those observed in the case of deoxycholic acid (DCA) and apocholic acid (ACA). Consequently, it is considered that there exist one-dimensional molecular assemblies of the monomers in one-dimensional spaces at a molecular level, called channels. Crystallographic studies show that MC forms amphiphilic bilayered assembly. It is expected that sliding of the bilayers along the lipophilic side yields channels between the layers like the cases of cholic acid (CA), DCA, and ACA. Side pockets of the channels are slightly different in the size and shape among these hosts. The difference is closely related to slight differences of the polymerization behaviors among the hosts, called space effects.
\end{abstract}

KEY WORDS Inclusion Polymerization / One-Dimensionality / Space Effects / Channels / Side Pockets / Relative Size / Methyl Cholate / Amphiphilic Bilayers / Crystal Structure / Molecular Graphics /

Inclusion polymerization can be recognized as a polymerization in a microscopic space at a molecular level. ${ }^{1}$ Since a host component provides an inherent space, the polymerization is characterized by an occurrence of the space effect. When the space is a channel and an interlayer space in inclusion compounds, we may observe a one- and two-dimensional character of the polymerization, respectively.

We so far studied the one-dimensional polymerization by using of a pair of hosts, deoxycholic acid $(3 \alpha, 12 \alpha$-dihydroxy-5 $\beta$-cholan-24- oic acid, DCA) and apocholic acid $(3 \alpha, 12 \alpha$-dihydroxy-5 $\beta$-chol-8(14)-en-24-oic acid, ACA). ${ }^{2,3}$ Recently, we found that the related compounds, such as cholic acid $(3 \alpha, 7 \alpha, 12 \alpha$-trihy- droxy-5 $\beta$-cholan-24-oic acid, CA), ${ }^{4-6}$ methyl cholate (MC), ${ }^{7,8}$ and methyl deoxycholate ${ }^{9}$ form the inclusion compounds. We may expect that these compounds also serve as a set of the hosts suitable for the one-dimensional inclusion polymerization.

However, it must be kept in mind that even though a set of the hosts have similar molecular structures, their molecular assemblies often differ greatly from one another. For example, a pair of CA and DCA constitute such a case. CA has an additional hydroxyl group as compared with DCA, leading to a different hydrogen-bonding network amomg the host molecules. The molecular assembly of CA has channels with larger pockets than those of

* Present address: Department of Chemistry, Faculty of Engineering, Gifu University, Gifu, Gifu 501-11, Japan. To whom correspondence should be addressed. 
DCA and ACA. ${ }^{5,6}$ Consequently, CA has a different inclusion ability from DCA and ACA. Another example is provided by a set of methyl esters of these hosts. Methyl ester of DCA, unlike DCA, assembles in a different mode to yield no channels, ${ }^{9}$ whereas methyl ester of $\mathrm{CA}(\mathrm{MC})$, like $\mathrm{CA}$, forms the inclusion compounds with a variety of organic substances. ${ }^{7,8}$

We can observe the space effect at a molecular level in the one-dimensional inclusion polymerization, when a set of hosts form similar assemblies to leave a set of finely different channels and further to include the same guests in common. From this viewpoint a well-known pair of urea and thiourea do not serve as such an example. The reason is that they can not include the same monomers in common, although these hosts surely form similar hexagonal channels. However, a pair of ACA and DCA serve as a good example. On the basis of a fact that ACA forms larger channels than DCA,${ }^{18}$ we confirmed the space effects from various viewpoints for the first time. ${ }^{1-3}$

Advantageously, it was found that MC serves as the third host suitable for the one-dimensional inclusion polymerization in addition to a pair of DCA and ACA as reported previously. ${ }^{10}$ Thereafter, we obtained crystallographic evidence which supports an existence of channels between amphiphilic bilayers. ${ }^{11}$ In addition, molecular graphics studies gave us visual and valuable information about the size and shape of the channels and their side pockets. $^{6,12}$ It seems that a comparison of the channels and pockets leads us to a possible explanation of the space effects among these hosts mentioned above. We try in this paper to understand various behaviors in the polymerization by using $\mathrm{MC}$ as a host on the basis of crystal structures of $\mathrm{MC}$ inclusion compounds.

\section{EXPERIMENTAL}

\section{Materials}

MC used was prepared from commercially available CA (Sigma Co.) by esterification with methanol containing hydrogen chloride, ${ }^{13}$ further purified by recrystallization from methanol. Solvent-free MC was obtained by heating at $110^{\circ} \mathrm{C}$ for $20 \mathrm{~h}$ under reduced pressure or by recrystallization from ethyl acetate-hexane. 1,3-Pentadiene, 2-methyl-1,3butadiene, and vinyl monomers were commercially available and used without further purification. 2,3-Dimethyl-1,3-butadiene, ${ }^{14} 1$ carbomethoxy-1,3-butadiene, ${ }^{15}$ 1-cyano-1,3butadiene, ${ }^{16}$ 1-chloro-1,3-butadiene, ${ }^{17}$ were prepared according to literature.

\section{Formation of Inclusion Compounds and Their Polymerization}

The inclusion compounds of a monomer with $\mathrm{MC}$ was prepared as follows. $1.0 \mathrm{~g}$ of the solvent-free MC and an equimolar amount of a monomer were placed in a glass tube of $10 \mathrm{~mm}$ diameter, which was sealed under vacuum $\left(10^{-3}\right.$ Torr) after three freeze-thaw cycles. The tube was allowed to stand at $25^{\circ} \mathrm{C}$ for $20 \mathrm{~h}$ to form the inclusion compounds, and then exposed to $\gamma$-irradiation from a ${ }^{60} \mathrm{Co}$ source at a definite temperature for one hour with a total dose of $1.0 \mathrm{Mrad}$. After the irradiation the tube was allowed to stand at a definite temperature in order to post-polymerize and then cooled again to $-78^{\circ} \mathrm{C}$. The contents were immediately poured into an excess amount of methanol to separate the polymer from MC. The methanol-insoluble fraction was filtered, dried under vacuum and weighed.

\section{Measurements}

Melting points of MC-polymer inclusion compounds were determined on a hot-stage polarizing microscope and were uncorrected. The molecular weight of the polymers was estimated by gel permeation chromatography and viscometry. Infrared (IR) spectra were 
obtained by using a $\mathrm{KBr}$ disk or a film. ${ }^{1} \mathrm{H}$ and ${ }^{13} \mathrm{C}$ NMR were measured at $100 \mathrm{MHz}$ with a JEOL JNM-RS-100 spectrometer and at $15 \mathrm{MHz}$ with a JEOL JNM FX-60s spectrometer, respectively. Specific optical rotation of polymers was measured in chloroform-benzene solution $(50: 50, \mathrm{v} / \mathrm{v})$ on a JASCO DIP 181 digital polarimeter. Thermogravimetry (TG) and differential thermal analysis (DTA) were carried out by using a SEIKO I\&E SSC 580 DS instrument. The scans were taken at a speed of $5^{\circ} \mathrm{Cmin}^{-1}$ under nitrogen atmosphere. ESR spectra were performed by a VARIAN E-109 spectrometer equipped with an automatic temperature control operating at $\mathrm{X}$-frequency band.

\section{RESULTS AND DISCUSSION}

\section{Properties of MC Inclusion Compounds}

The inclusion compounds of MC are usually prepared by a recrystallization and/or an absorption method. The formation of the compounds is readily confirmed by a combination of DTA and TG with IR and NMR spectroscopy. For example, in the case of methanol-included MC which was obtained by esterification of CA in methanol, it is clear from their measurements that the crystals include an equimolar amount of methanol, as shown in Figures 1(b) and 2(b). Solvent-free MC was obtained by heat treatment at $110^{\circ} \mathrm{C}$ under reduced pressure (Figures 1(a) and 2(a)).

We isolated the inclusion compounds with vinyl monomers by direct recrystallization of the solvent-free MC from large amounts of the liquid monomers. As for thermally stable compounds, we could determine molar ratios of the compounds by DTA and TG measurements. The absorption method yielded the same compounds with these monomers.

For example, Figures 1(c) and 1(d) show DTA and TG diagrams of the compounds of MC with acrylonitrile and 2-chloroacrylonitrile, respectively. Each DTA diagram has two kinds of peaks. The peak at lower temperature

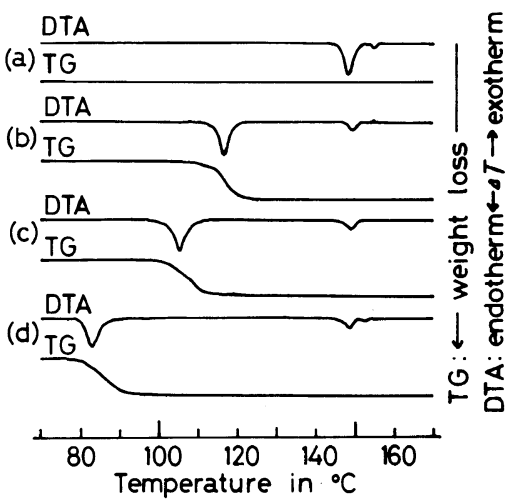

Figure 1. TG and DTA diagrams of the inclusion compounds of MC with (a) no guest, (b) methanol, (c) acrylonitrile, and (d) 2-chloroacrylonitrile.

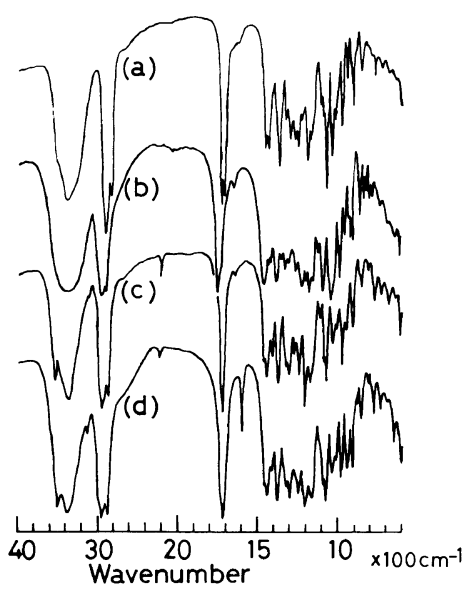

Figure 2. Infrared spectra of the inclusion compounds of MC with (a) no guest, (b) methanol, (c) acrylonitrile, and (d) 2-chloroacrylonitrile.

corresponds to the temperature at which the corresponding included monomer is released from the MC crystals. The TG measurement indicated that the molar ratio of $\mathrm{MC}$ to the monomer amounts nearly unity. The peak at higher temperature corresponds to the melting point of MC itself. Figures 2(c) and 2(d) show IR spectra of the inclusion compounds with the monomers. In addition to an existence of the guest component, it can be seen from a comparison of Figures 2(a)-(d) that absorption bands due to hydroxyl and carbonyl groups are different from each other, indicating 
that the guest molecules induce different hydrogen-bonding networks in the molecular assemblies.

In the case of volatile diene monomers, we have a difficult problem of isolating the inclusion compounds. In the case of DCA and ACA, the compounds with such monomers can easily be prepared by recrystallization from methanol or ethanol containing the monomers. But we can not use the alcohols as the solvents in the case of $\mathrm{MC}$, since $\mathrm{MC}$ forms the stable inclusion compounds with the alcohols. We do not find an alternative solvent yet, and we fail to isolate the inclusion compounds of $\mathrm{MC}$ with the monomers. It seems that the compounds are not stable at ordinary temperature and pressure. Therefore, we employed an absorption method for obtaining the compounds with the monomers in sealed tubes and applied them to the inclusion polymerization without isolating.

\section{Polymerizability of Monomers in MC Inclusion Compounds}

We studied the inclusion polymerization of various monomers in a similar way to the case of DCA and ACA. ${ }^{2}$ The degassed and sealed tubes were exposed to $\gamma$-irradiation from a ${ }^{60} \mathrm{Co}$ source at -78 or $0^{\circ} \mathrm{C}$. The post-polymerization was done at various temperatures. The results are summarized in Table I. In the absence of the host, only a trace amount of polymers yielded.

During the polymerization procedure, the crystalline inclusion compounds were found to keep their original shape and appearance. After the polymerization, the compounds melted at lower temperatures than the melting point of MC itself. These points are considered to be the melting points of the polymer inclusion compounds. The lowering of the melting points was notable in the case of 1-carbomethoxy1,3-butadiene and methyl methacrylate, as shown in Table I.

Polymerizabilities of the monomers depended on the size and shape of the monomers

Table I. Inclusion polymerization of various vinyl and diene monomers by using $\mathrm{MC}$ as a host $\mathrm{a}^{\mathrm{a}}$

\begin{tabular}{|c|c|c|c|c|c|c|c|}
\hline & \multirow{3}{*}{ Monomer ${ }^{b}$} & \multicolumn{2}{|c|}{ Postpolymn. } & \multirow{3}{*}{$\frac{\text { Conv. }}{\%}$} & \multirow{3}{*}{$\begin{array}{c}\text { Mp of polymer } \\
\text { adduct }\end{array}$} & \multirow{3}{*}{$M_{w}$} & Microstructure \\
\hline & & \multirow{2}{*}{$\frac{\text { Temp }}{{ }^{\circ} \mathrm{C}}$} & \multirow{2}{*}{$\begin{array}{l}\text { Time } \\
\text { Day }\end{array}$} & & & & $1,4-$ trans $^{\mathrm{e}}$ \\
\hline & & & & & & & $\%$ \\
\hline \multirow{6}{*}{ (A) } & $\mathrm{R}_{1}=\mathrm{CH}_{3}, \mathrm{R}_{2}=\mathrm{R}_{3}=\mathrm{H}$ & 30 & 4 & 6 & $136-139$ & $-^{c}$ & 50 \\
\hline & $\mathrm{R}_{1}=\mathrm{R}_{2}=\mathrm{CH}_{3}, \mathrm{R}_{3}=\mathrm{H}$ & 30 & 4 & 19 & $154-156$ & $\complement^{\mathrm{d}}$ & 90 \\
\hline & $\mathrm{R}_{1}=\mathrm{R}_{2}=\mathrm{H}, \mathrm{R}_{3}=\mathrm{CH}_{3}$ & 30 & 7 & 50 & $142-144$ & $8.2 \times 10^{3}$ & 68 \\
\hline & $\mathrm{R}_{1}=\mathrm{R}_{2}=\mathrm{H}, \mathrm{R}_{3}=\mathrm{CO}_{2} \mathrm{CH}_{3}$ & 70 & 1 & 49 & $128-132$ & $5.0 \times 10^{3}$ & 95 \\
\hline & $\mathrm{R}_{1}=\mathrm{R}_{2}=\mathrm{H}, \mathrm{R}_{3}=\mathrm{CN}$ & 70 & 2 & 46 & $143-145$ & $1.6 \times 10^{4}$ & 90 \\
\hline & $\mathrm{R}_{1}=\mathrm{R}_{2}=\mathrm{H}, \mathrm{R}_{3}=\mathrm{Cl}$ & 30 & 4 & 46 & $133-135$ & $\ldots$ d & 95 \\
\hline \multirow{4}{*}{ (B) \{} & & -30 & 2 & 26 & $78-81$ & $5.1 \times 10^{5}$ & \\
\hline & $\begin{array}{l}\mathrm{K}_{1}=\mathrm{CH}_{3} \\
\mathrm{R}_{2}=\mathrm{CO}_{2} \mathrm{CH}_{3}\end{array}$ & & 2 & 20 & 01 & t & rich \\
\hline & $\mathrm{R}_{1}=\mathrm{CH}_{3}, \mathrm{R}_{2}=\mathrm{CN}$ & 70 & 2 & 96 & $158-160$ & $1.1 \times 10^{6}$ & Atactic \\
\hline & $\mathrm{R}_{1}=\mathrm{Cl}, \mathrm{R}_{2}=\mathrm{CN}$ & 70 & 2 & 47 & $150-152$ & $-^{c}$ & Atactic \\
\hline
\end{tabular}

a $\mathrm{MC}, 1.0 \mathrm{~g}$; molar ratio of feed; $\mathrm{MC} /$ monomer $=1 / 1 ; \gamma$-ray irradiation, $1.0 \mathrm{Mrad}, 0^{\circ} \mathrm{C}$ for diene monomers, $1.0 \mathrm{Mrad}$, $-78^{\circ} \mathrm{C}$ for vinyl monomers.

b (A) $\mathrm{CH}_{2}=\mathrm{C}\left(\mathrm{R}_{1}\right) \mathrm{C}\left(\mathrm{R}_{2}\right)=\mathrm{CH}\left(\mathrm{R}_{3}\right) ;(\mathrm{B}) \mathrm{CH}_{2}=\mathrm{C}\left(\mathrm{R}_{1}\right)\left(\mathrm{R}_{2}\right)$.

c Not determined due to unstable and insoluble polymers.

${ }^{d}$ Inherent viscosity $\left(\eta_{\text {sp }} / c\right)$ of a $0.4 \mathrm{~g} \mathrm{dl}^{-1}$ solution in $o$-dichlorobenzene at $30^{\circ} \mathrm{C}$ was $0.06 \mathrm{~g} \mathrm{dl}^{-1}$.

e In the case of 1,3-butadiene derivatives. 
rather than their electronic properties. For example, we obtained a trace and small amount of polymers in the case of 1,3-butadiene and 2-methyl-1,3-butadiene(isoprene), respectively. Other monomers having an alkyl group, such as ethyl and isopropyl, at 2-position gave no polymers. However, in the case of 2,3-dimethyl-1,3-butadiene and 1,3-pentadiene, the polymer yields increased up to 19 and $50 \%$ yield, respectively. 1,3-Butadiene derivatives having a polar group at 1-position gave the corresponding polymers, as shown in Table I.

However, other derivatives, such as 4methyl-1,3-pentadiene, 2,4-dimethyl-1,3-pentadiene, 1,4-dicyano-1,3-butadiene, 1-cyano1,3-pentadiene did not give the corresponding polymers, when post-polymerized at $50^{\circ} \mathrm{C}$ for 4 days.

The polymer yields tend to increase with increasing the post-polymerization time and temperature. As an example, we studied the post-polymerization of 2,3-dimethyl-1,3-butadiene in detail. Figure 3 shows the resulting relationship between the time and the polymer yields. It can be seen that the polymerization proceeds fast in the early stage, then gradually and saturates. Such a saturation of the polymer yield was observed within $24 \mathrm{~h}$ at $100^{\circ} \mathrm{C}$.

Acrylonitrile did not yield the corresponding polymers, when post-polymerized at different temperatures ranging from -78 to $70^{\circ} \mathrm{C}$. Other vinyl monomers, such as methacrylonitrile, 2-chloroacrylonitrile and methyl acrylate, gave the corresponding polymers in good yields.

\section{Microstructures of the Resulting Polymers}

The resulting polymers contained some regular microstructures in the case of diene monomers, while no regular ones in the case of vinyl monomers.

Diene Monomers with Alkyl Groups. The resulting poly(1,3-pentadiene) consists of about $2: 1$ ratio of 1,4-trans-addition to 1,4 -cisaddition and several percent of 1,2-addition based on the ${ }^{1} \mathrm{H}$ and ${ }^{13} \mathrm{C}$ NMR spectra. The

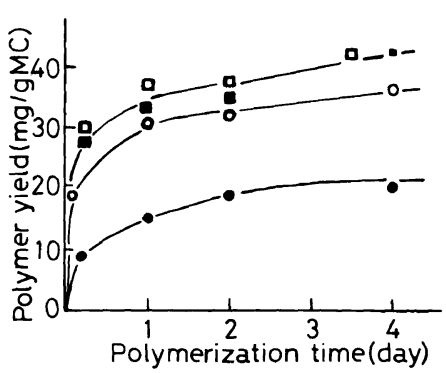

Figure 3. Temperature dependence of the post-polymerization of 2,3-dimethyl-1,3-butadiene by using $\mathrm{MC}$ as a host. Postpolymerization temperature: $(O) 0,(O) 30$, (ם) 50 , and $(\square) 100^{\circ} \mathrm{C}$. MC, $1.0 \mathrm{~g}$; the monomer, $0.25 \mathrm{ml}$; $\gamma$-irradiation dose, $1.0 \mathrm{Mrad}$ at $-78^{\circ} \mathrm{C}$.

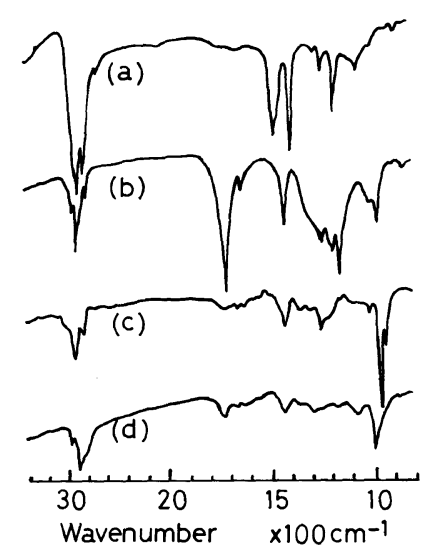

Figure 4. Infrared spectra of the polymers obtained by the inclusion polymerization of (a) 2,3-dimethyl-1,3butadiene, (b) 1-carbomethoxy-1,3-butadiene, (c) 1-chloro1,3-butadiene, and (d) 1-bromo-1,3- butadiene by using $\mathrm{MC}$ as a host.

microstructure is similar to that of a polymer obtained by free-radical polymerization.

On the other hand, the resulting poly $(2,3-$ dimethyl-1,3-butadiene) had some stereoregularities. ${ }^{19-21}$ The melting point $(257-$ $260^{\circ} \mathrm{C}$ ) is near that of 1,4 -trans polymer $\left(267-272^{\circ} \mathrm{C}\right)$ and far from that of 1,4 -cis polymer $\left(182-192^{\circ} \mathrm{C}\right)$. As shown in Figure 4(a), the IR spectrum of the polymer have no absorption bands at $1630 \mathrm{~cm}^{-1}$ and $890 \mathrm{~cm}^{-1}$ characteristic of 1,2-addition, whereas a strong band at $1150 \mathrm{~cm}^{-1}$ characteristic of 1,4-transaddition. In the ${ }^{13} \mathrm{C}$ NMR spectra measured 
in $o$-dichlorobenzene, methyl and methylene resonances appear at 1.77 and $2.16 \mathrm{ppm}$ in the case of 1,4-trans-addition as well as 1.73 and $2.24 \mathrm{ppm}$ in the case of 1,4-cis-addition, respectively, while no signal for 1,2-addition was observed. The content of 1,4-transaddition was more than $90 \%$ at $-20^{\circ} \mathrm{C}$ and decreased to about $80 \%$ with increasing the post-polymerization temperature.

Diene Monomers with Polar Groups. In the case of 1-carbomethoxy-1,3-butadiene, the post-polymerization produced a colorless solid polymer. The IR, ${ }^{1} \mathrm{H}$, and ${ }^{13} \mathrm{C}$ NMR spectra indicate that the polymers predominantly consist of 1,4-trans structure. For example, Figure 4(b) shows the IR spectrum of the polymer obtained by the post-polymerization at $30^{\circ} \mathrm{C}$ for 4 days. Moreover, the polymer had a relatively high value of specific optical rotation $\left([\alpha]_{\mathrm{D}}^{20}-27^{\circ}\right.$ in chloroform-benzene). ${ }^{22}$

In the case of 1-chloro-1,3-butadiene, the post-polymerization at $0^{\circ} \mathrm{C}$ gave a colorless solid polymer. Figure 4(c) shows IR spectra of the polymer. The absorption bands at 1650 and $960 \mathrm{~cm}^{-1}$ are assigned to $\mathrm{C}=\mathrm{C}$ stretching and $\mathrm{C}-\mathrm{H}$ bending vibration of trans double bond, respectively. The polymer had a low value of specific optical rotation $\left([\alpha]_{D}^{25}-3^{\circ}\right.$ in $\left.\mathrm{CHCl}_{3}\right){ }^{23}$ These results indicate that the polymer consists predominantly of head-totail, 1,4-trans structure. This is supported by an occurrence of dehydrochlorination of the polymer. ${ }^{24}$ The color of the polymer turned through pale yellow to purple color after 15 $\mathrm{h}$ on standing at room temperature. As shown in Table II, the dehydrochlorination of the resulting polymers increased with increasing the post-polymerization temperature.

The polymerization of 1-bromo-1,3-butadiene also yielded polymers composed of 1,4-trans-addition, as indicated from the IR spectrum (Figure 4(d)). The dehydrobromination proceeded at a fairly high rate and amounted to $60 \%$, when post-polymerized at $70^{\circ} \mathrm{C}$ for one day. The post-polymerization of
Table II. Properties of poly(1-chlorobutadiene)s obtained by inclusion polymerization by using $\mathrm{MC}^{\mathrm{a}}$

\begin{tabular}{ccccc}
\hline \multicolumn{2}{c}{ Postpolymn. } & & \\
\cline { 1 - 1 } Temp & Time & & $\begin{array}{c}\text { Color of } \\
\text { polymer }\end{array}$ & $\begin{array}{c}\text { Loss of } \\
\text { chlorine }\end{array}$ \\
\cline { 1 - 1 }${ }^{\circ} \mathrm{C}$ & $\mathrm{h}$ & & & $\%$ \\
\hline 0 & 96 & & white & 2.4 \\
30 & 96 & & pink & 5.1 \\
50 & 72 & & violet & 20 \\
70 & 72 & & violet & 19 \\
90 & 2.5 & black & 32 \\
\hline
\end{tabular}

${ }^{a} \mathrm{MC}, 1.0 \mathrm{~g}$; molar ratio of feed, MC/1-chloro-1,3butadiene $=1 / 1 ; \gamma$-ray irradiation $=1.0 \mathrm{Mrad}$.

1-cyano-1,3-butadiene yielded polymers with a high 1,4-trans content.

Vinyl Monomers. Methacrylonitrile polymerized in a high yield, when post-polymerized at $70^{\circ} \mathrm{C}$ for two days. 2-Chloroacrylonitrile polymerized to yield violet and insoluble polymers in a good yield. The polymerization of methyl acrylate and methacrylate at $-30^{\circ} \mathrm{C}$ for two days gave the polymers with conversions of 5 and $26 \%$, respectively. The resulting polymers did not show any significant differences in the microstructures from polymers obtained by free-radical polymerization in solution.

\section{ESR Study of the Propagating Radicals}

In the case of DCA and ACA, we observed clear ESR specra of propagating radicals, indicating that the polymerization in the channels proceeds by a free-radical mechaism. $^{2,25}$ Also in the case of MC, we detected the ESR spectra in the case of diene monomers. However, most of the spectra were complex and difficult to analyze. It is considered that the complexity arises from an overlap of spectra derived from the host with ones derived from the propagating radicals.

The best ESR spectra of the propagating radicals were observed in the case of 1-carbomethoxy-1,3-butadiene. ${ }^{10}$ Starting from the 
measurement below $-120^{\circ} \mathrm{C}$ after $\gamma$-irradiation, the ESR signals due to the host radicals disappeared with increasing the temperature prior to the ones due to the propagating radicals. Although total intensity of the signal decreased, a clear spectrum of the propagating radicals remained even at $0^{\circ} \mathrm{C}$. The spectrum consists of four lines with a hyperfine splitting of about $1.7 \mathrm{mT}$, and are well assigned to an allylic radical. The intensity distribution did not change until the spectrum disappeared at $100^{\circ} \mathrm{C}$. The disappearance of the ESR signal is in contrast to the case of DCA and ACA, where the radicals were stable even at $100^{\circ} \mathrm{C}^{3,10}$ Also in the case of 2,3-dimethyl-1,3-butadiene, the propagating radicals still remained even at room temperature, although the radicals derived from other alkyl-substituted butadienes disappeared.

\section{Crystallographic Study of the Inclusion Spaces}

We still have no direct evidence which shows an existence of the channels on the basis of crystal structure analysis of MC inclusion compounds. But we recently obtained a strong support from a crystallographic viewpoint. CA shows guest-dependent polymorphism by an exchange of multiple hydrogen-bonding networks and conformations of the side chain. ${ }^{26}$ Likewise, it was found that MC has also polymorphic crystal forms based on the same mechanism. We determined a crystal structure of the inclusion compound of $\mathrm{MC}$ with acrylonitrile $^{11}$ in addition to that with methanol. ${ }^{7}$ The former structure is more closely related to that of channel-type inclusion compound of $\mathrm{CA}^{5,6}$ than the latter. Accordingly, a comparison of these structures provides us valuable information of the channels formed between organic bilayers, as described below.

MC, like CA, DCA, and ACA, are facial amphiphilic molecules, since they are composed of one hydrophilic and another lipophilic site. ${ }^{27}$ These host molecules assemble in various modes to form similar pleated sheets composed of one hydrophilic and another
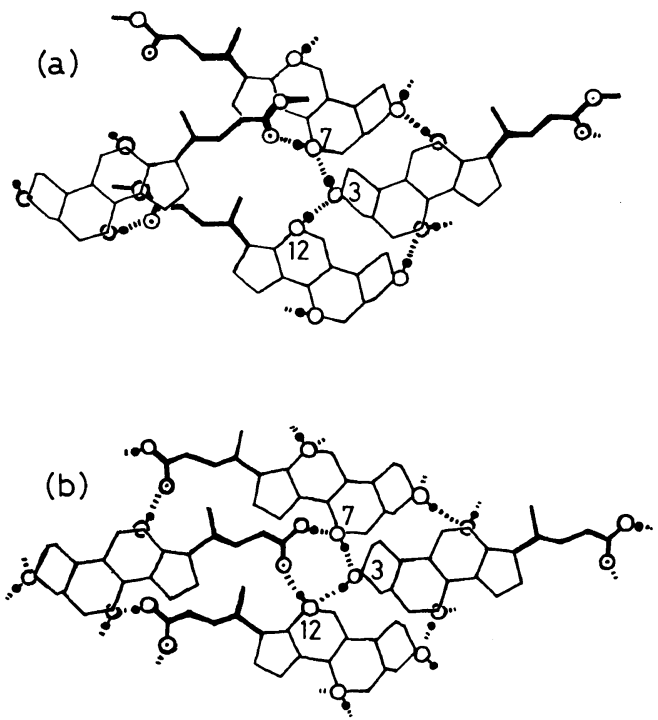

Figure 5. Hydrogen-bonding networks of the bilayers of the inclusion compounds of (a) MC with acrylonitrile and (b) CA with $\gamma$-valerolactone.

lipophilic sides, and the sheets stack to form amphiphilic bilayers. The bilayers can slide each other along lipophilic sides on the basis of lots of crystallographic studies on the inclusion compounds of DCA. ${ }^{28}$

The crystal of $\mathrm{MC}$ with acrylonitrile has the same space group $\left(P 2_{1}\right)$ as that of CA with $\gamma$-valerolactone. ${ }^{6}$ As shown in Figure 5, the bilayers of both crystals are formed by the same assembly mode. Four host molecules provide each functional group to form similar hydrogen-bonding networks. It is noteworthy that the side chains attached to the steroidal skeleton locate in different sites between these two cases. That is, the carboxylic part of CA connect two hydroxyl groups at 7- and 12-positions in the steroidal skeleton to form a cyclic hydrogen-bonding network, while the esteric part of MC connects the hydroxyl group only at 7-position.

Molecular graphics of the crystals gives information of a more subtle variety than available by other methods. MODRASTE ${ }^{29}$ is an excellent software for analyzing the channels, because we can cut and slice the 


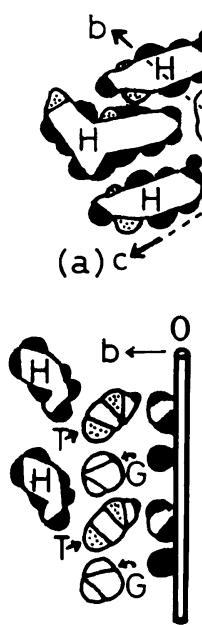

(b) 
at a molecular level, called channels. ${ }^{1}$

The further remarkable feature is an existence of the "space effect" at a molecular level. That is, an arrangement and movement of the included molecules should be different depending on the relative size between the molecules and the channels. The same molecules would be loosely included in larger channels, while tightly held in smaller ones. The slight difference yields various slight different behaviors of the polymerization at a molecular level. We found that the behaviors in the case of MC are slightly different from those in the case of DCA and ACA. For example, the stability of the propagating radicals as well as the stereoregularities of the resulting polymers are lower in the former than in the latter. All of the results are consistent with an idea that the MC channels are larger than those of DCA and ACA, but smaller than that of CA. The idea is supported by the following crystallographic results. DCA has a rectangular channel with very small pockets, while CA has a pentagonal one with large pockets. ${ }^{5,6}$ As the esteric part of MC occupies a part of the large pocket of $\mathrm{CA}$, the pockets of $\mathrm{MC}$ are smaller than those of CA. So, the channels of $\mathrm{MC}$ are intermediate in size between those of CA and DCA.

In conclusion, we may consider that $\mathrm{MC}$ provide a channel suitable for a systematic study on the one-dimensional inclusion polymerization. The study may contribute to clarify the space effect on the polymerization, because the channel of $\mathrm{MC}$ is smaller in size than that of CA, but larger than those of DCA and ACA.

Acknowledgements. The authors wish to thank the Radiation Laboratory, the Institute of Scientific and Industrial Research, Osaka University, for allowing them to use the ${ }^{60} \mathrm{Co}$ facilities. We thank Professor M. Kamachi, Faculty of Science, Osaka University, for his valuable discussion. We also thank Associate Professor K. Miki, Research Laboratory of
Resources Utilization, Tokyo Institute of Technology, for X-ray crystal structural analysis. The work was partly supported by a Grant-in-Aid for Scientific Research from the Ministry of Education, Science, and Culture of Japan.

\section{REFERENCES}

1. M. Miyata, "Polymerization in Constrained Media" in "Polymerization in Organized Media," C. M. Paleos, Ed., Gordon and Breach, New York, 1992, p 327.

2. M. Miyata, T. Tsuzuki, F. Noma, and K. Takemoto, Makromol. Chem. Rapid Commun., 9, 45 (1988).

3. K. Takemoto and M. Miyata, Mol. Cryst. Liq. Cryst., 186, 189(1990).

4. M. Miyata, M. Shibakami, W. Goonewardena, and K. Takemoto, Chem. Lett., 605 (1987).

5. K. Miki, A. Masui, N. Kasai, M. Miyata, M. Shibakami, and K.Takemoto, J. Am.Chem. Soc., 110, 6594 (1988).

6. K. Miki, N. Kasai, M. Shibakami, K. Takemoto, and M. Miyata, J. Chem. Soc., Chem. Commun., 1757 (1991).

7. M. Miyata, W. Goonewardena, M. Shibakami, K. Takemoto, A. Masui, K. Miki, and N. Kasai, J. Chem. Soc., Chem. Commun., 1140 (1987).

8. K. Miki, A. Masui, N. Kasai, W. Goonewardena, M. Shibakami, K. Takemoto, and M. Miyata, Acta Cryst., C48, 503 (1992).

9. K. Miki, A. Masui, N. Kasai, M. Miyata, W. Goonewardena, M. Shibakami, and K. Takemoto, Acta Cryst., C45, 79 (1989).

10. W. Goonewardena, M. Miyata, and K. Takemoto, Polym. J., 23, 1405 (1991).

11. W. Goonewardena, M. Miyata, and K. Takemoto, unpublished results.

12. M. Miyata, K. Sada, K. Hirayama, Y. Yasuda, and K. Miki, Supramol. Chem., in press.

13. A. F. Hofmann, Acta Chem. Scand., 17, 173 (1963).

14. C. F. Allen and A. Bell, "Organic Synthesis," Coll. Vol. III, John Wiley \& Sons, New York, 1955, p 312.

15. E. P. Kohler and F. R. Butler, J. Am. Chem. Soc., 48, 1043 (1926).

16. I. E. Muskat and H.E.Northrup, J. Am. Chem. Soc., 52, 4043 (1930).

17. H. R. Snyder, J. M. Stewart, and R. L. Myers, $J$. Am. Chem. Soc., 71, 1055 (1949).

18. H. C. Chang, R. Popovitz-Biro, M. Lahav, and L. Leiserowitz, J. Am. Chem. Soc., 109, 3883 (1987).

19. J. F. Brown and D. M. White, J. Am. Chem. Soc., 82, 5671 (1960).

20. M. Miyata, K. Morioka, and K. Takemoto, J. Polym. Sci., Polym. Chem., 15, 2987 (1977). 
21. D. Blondin, J. Regis, and J. Prud'homme, Macromolecules, 7, 187 (1974).

22. M. Miyata, S. Akizuki, H. Tsutsumi, and K. Takemoto, J. Polym. Sci. Polym. Lett., 26, 229 (1988).

23. H. Tsutsumi, K. Okanishi, M. Miyata, and K. Takemoto, J. Polym. Sci., Polym. Chem., 28, 1527 (1990).

24. H. Tsutsumi, K. Okanishi, M. Miyata, and K. Takemoto, J. Macromol. Sci.-Chem., A26, 1335 (1989).

25. M. Miyata, F. Noma, Y. Osaki, K. Takemoto, and
M. Kamachi, J. Polym. Sci. Polym. Lett., 24, 457 (1986).

26. M. Miyata, K. Sada, S. Hori, and K. Miki, Mol. Cryst. Liq. Cryst., 219, 71 (1992).

27. Y. Cheng, D. M. Ho, C. R. Gottlieb, and D. Kahne, J. Am. Chem. Soc., 114, 7319 (1992).

28. E. Giglio, "Inclusion Compounds," Vol. 2, J. L. Atwood, J. E. D. Davies, and D. D. MacNicol, Ed., Academic Press, London, 1984, p 207.

29. H. Nakano, "Molecular Graphics," Science House, Tokyo, 1987. 